XXXIV.

\title{
FURTHER REMARKS ON THE USE OF NITRATE OF SILVER APPLIED WITHIN THE MOU'TH OF THE EUSTACHIAN TUBE FOR THE RELIEF OF TINNITLS.*
}

\author{
By William C. Braisi.in, M. D.,
}

Brooklys.

The following notes aim to elaborate certain points of a paper read before this society two years ago on the use of silver nitrate applied within the eustachian tube for the relief. of tinnitus, especially as to technic and results.

TECH NIC.

Though medicaments have been applied to the interior of the tube by the syringe, bougies and other methods, the manner of application found by the writer to be the simplest and most generally useful is by a cotton tipped wire. The wire employed is composed of two thin silver strands twisted firmly into one. This wire gives the proper strength, resilience and elasticity needed for the purpose, and was suggested, I believe, by $\mathrm{Dr}$. Sidney Yankauer, and made by Tiemann.

The small bit of cotton for carrying the medication is wound on one end of the wire firmly and smoothly. In winding on, the bit of cotton is laid against the wire. and the wire is then rolled toward the right, as in driving a screw. The wire is likewise rolled in the same direction when within the eustachian tube if this is found necessary to facilitate its passage, and for surmounting folds or ridges of mucous membrane within the tube, when present. The size of the cotton pledget wound on the end of the wire is rarely more than double the diameter of the wire: but in marked swelling at and about the mouth of the eustachian tube, larger pledgets are used for application within the trumpet-like expansion of the tube only. The

* Read before the meeting of the American Otological Association, May 26, 1914. 
deeper applications of the small sized pledgets are reserved for subsequent applications. The fibers of cotton projecting beyond the end of the wire are bent over to mark the end of the wire, and are then trimmed off smoothly with scissors in order to prevent the projecting fibers, unsupported by the wire, from doubling within the tube. The cotton pledget is then tested to see that it cannot be pulled off the wire, but is not dipped into the solution until after inflation of the tube, just before the wire is introduced into the catheter.

The strength of silver nitrate solution employed is usually twenty grains to the ounce (four per centum), though a strength of eighty grains to the ounce has been used when the application is not to be repeated within a week or longer.

REMOVAL OF PLEDGET AFTER USE.

If the wisp of cotton is moulded on the wire as firmly as it should be, it cannot be pulled off, and is only with difficulty trimmed off with scissors curved on the flat. It is most easily removed from the wire by burning in the alcohol flame.

Under this treatment the wires may become bent or brittle. Bends and angles are readily removed by passing the length of the wire held at a slight tension slowly through the flame. As soon as a wire shows signs of becoming brittle, it is discarded.

\section{RESULTS.}

I need hardly say that we may expect to obtain no relief from tinnitus due to lesions of the auditory nerve or of the central nervous system by this method. Congestion and swelling of the tubal mucous membrane, so generally accompanied by tinnitus, seem to me to be more rapidly relieved when, in addition to the other generally employed measures, local applications of silver are made. Operative measures increasing the patency of the posterior part of the nose sometimes alone give prompt and permanent relief of tinnitus, especially the removal of spurs causing pressure on the opposed turbinates.

Digestive, circilatory and general diseases, if present, are factors which nearly always play a part in producing or aggravating tinnitus; yet the middle ear disease once started, no matter by whatever agency, requires, as a rule, active, even vigorous treatment directed toward restoring the normal patency of the eustachian tube. 